\title{
CONGENITAL TOXOPLASMOSIS
}

\author{
REPORT OF TWO CASES
}

\author{
BY \\ H. G. FARQUHAR, B.M., B.Ch., M.R.C.P., D.C.H. \\ Honorary Assistant Physician, The Royal Liverpool Children's Hospital, \\ and \\ W. M. L. TURNER, M.D., M.R.C.P. \\ Late House Physician, The Royal Liverpool Children's Hospital \\ (From the Department of Child Health, the University of Liverpool)
}

Infection of man with the protozoon toxoplasma in its various manifestation has now been described in an extensive literature mainly from America, but also more recently from Sweden (Magnusson, 1947), Denmark (Boesen, 1948), Holland (Binkhorst, 1947), and Switzerland (Bamatter, 1947).

With the exception of the case report by Jacoby and Sagorin (1948), published after this paper had been prepared for press, no other reports of cases of toxoplasmosis which can be regarded as established have been printed in this country. Reference should be made to the three cases described by Parsons (1946), though these were not confirmed by serological tests, and were later considered as not fulfilling the criteria provisionally required to justify the diagnosis of toxoplasmosis.

Though one of the earliest descriptions of the disease may be ascribed to Janku (1923), the condition was first summarized and proved by animal transmission by Wolf et al. (1939a, b; 1940). Excellent summaries may also be found in the writings of Sabin (1942), Callahan et al. (1946), and Schwartzman et al. (1948).

In man the disease has been described in four more or less distinct forms which vary with the age of the patient. The first is an infection affecting the foetus and the newborn child; this, the congenital type of the disease, being relevant to the present paper, will be described in fuller detail later. The second form is recognized as an encephalitis affecting older children. The third form shows itself as an acute febrile exanthematic illness affecting adults. Finally, there is a mild and apparently symptomless type of infection which may be recognized only by finding specific antibodies in the blood, or by the patient's giving birth to an infected infant.

\section{Congenital Toxoplasmosis}

The clinical and laboratory findings in this type of the disease are now becoming more clearly defined, and may be mentioned in the following categories:

1. Signs suggesting pathological changes in the central nervous system: tremor, spasticity, convulsions, microcephaly, hydrocephalus, mental retardation, and intracranial calcification.

2. Changes in the cerebrospinal fluid: xanthochromia, increase in protein, and pleocytosis, usually mononuclear.

3. Disorders of the eyes: ocular palsies, microphthalmos, vitreous opacities, and chorioretinitis affecting both eyes, especially in the macular region. Optic atrophy is found more rarely.

4. Demonstration of specific antibodies in the blood.

5. Isolation of the parasite from either the blood or other tissues.

6. Other occasional findings: anaemia, gastrointestinal symptoms, hepato-splenomegaly, pneumonitis, and myocarditis.

\section{Pathology}

Naturally occurring infections with this parasite have been found in a large number of animals, including cats, dogs, mice, rabbits, canaries, and sparrows. In animals infected either naturally or experimentally the disease is spread by the blood stream and most of the organs can be shown to contain parasites, though the brunt of the infection falls upon different viscera in the various species. Thus in the rabbit inoculated intracutaneously with virulent toxoplasma the brain is little affected, but in mice it is most commonly affected. In man it would appear that the distribution of the lesions depends upon the age of the subject, for in the adult the lungs seem specially liable to infection, though the liver, brain, myocardium, and other parts may also suffer. In the infant the central nervous 
system is mainly involved, and the disease usually takes the form of diffuse encephalomyelitis. Focal, yellow lesions, varying from a few $\mathrm{mm}$. in diameter up to $2 \mathrm{~cm}$. have been described in the brain cortex, the basal ganglia, midbrain, pons, medulla, and spinal cord. Sometimes these are found in the walls of the intracerebral ventricles where the ependyma is lost. The meninges become thickened and adherent to the superficial cortical nodules. Microscopically these lesions show extensive necrosis of the nervous and glial tissues with cavitation and calcification. An area of tissue reaction occurs around the necrotic areas, and may be recognized by dilatation of the capillaries and an infiltration by plasma cells, lymphocytes, neutrophils, eosinophils, and macrophages. Fibroblasts from the capillaries of the brain or the overlying meninges may lead to the formation of granulation tissue, and adhesions may thus develop between the lesions and the meninges. More distant still from the centre of the lesion a glial and microglial reaction can be recognized. The infecting parasites can be found in large numbers at the margin of the necrotic areas and also in the meningeal exudate.

Almost identical changes are found in the retina, disrupting its various layers, and at times leading to granulation tissue which invades the vitreous humour. The choroid coat shows less involvement but is oedematous. The lesion does not affect the sclera, but may extend along the optic nerve. Maldevelöpment of the eye such as microphthalmos would suggest that infection has occurred at an early stage of intra-uterine life.

Antibodies against toxoplasma may have been found in some infected animals and in man. They may be estimated by the neutralization test (Sabin, 1942), in which varying dilutions of a suspension of tissue infected with a virulent strain of toxoplasma and the unknown serum are injected intracutaneously into the back of a rabbit, and the resulting reaction measured. Complement fixation tests have also been used, but these have not been found very reliable. More recently an in vitro dye test for toxoplasma antibody has been developed (Sabin and Feldman, 1948).

\section{Case Histories}

Case 1. J.C. was prematurely born in the thirty-second week of pregnancy of a mother who had been well during the whole of her pregnancy. The delivery was described by her as a normal one, and the birth weight was $3 \mathrm{lb} .13 \mathrm{oz}$. Some cyanosis was noticed in the first three days of life, and the child was said to have been jaundiced from the fifth to the twelfth day.

The family history appeared to be a healthy one. The mother had suffered from chorea as a child. The father had been well all his life, and had served abroad during the 1939-45 war, visiting East and North Africa as well as Italy and France. There had been no previous children, and the mother had had no miscarriages. The home conditions were described as clean, and the only animal in the household was a dog. The blood of this animal as well as an excised lymph gland have so far failed to infect mice into which they were injected.

The child first attended the out-patient department at the age of thirteen weeks with a history of a feeding difficulty which had manifested itself as an excess of posseting. It was found, however, that, in spite of this sickness, he had gained $106 \mathrm{oz}$. since birth.

Examination revealed a rather pale-looking child with right sided microphthalmos (fig. 1) and obvious mental retardation. The skull measured fourteen and three-quarter inches in circumference, and there was an exaggerated Moro reflex to minor stimuli. No attempt was made to fix an object with the eyes, and the posture might have been regarded as normal for a child four weeks of age. There was slight stiffness of the lower limbs and a clonic response to the right knee jerk.

Examination of the eyes two weeks later revealed almost complete occlusion of the right pupil with posterior synechiae, and resolving areas of chorioretinitis with vitreous opacities. The left eye showed fewer synechiae but active choroidal infiltration of the nasal side of the fundus. Ten weeks later the eye lesions were described as settling down.

The child was admitted to hospital at the age of thirty-five weeks. The posseting had ceased within a few weeks of his first attendance, and the only complaint that the mother now had was that the child was unable to sit up, and that he did not appear to see very well.

Examination revealed very little that was new. He weighed $16 \mathrm{lb}$. $3 \mathrm{oz}$. The skull appeared even smaller than before in proportion to the rest of the body, and its circumference was $16 \frac{1}{4}$ inches. The smallness of the frontal bones was particularly marked, there being a palpable and visible step down from the parietal to the frontal bones over the vertex. An estimate of the mental development according to the Gesell norms gave a rating of between sixteen and twenty weeks. There was marked hypertonicity of the lower limbs.

INVESTIGATIONS. A radiograph of the skull at the age of thirteen weeks revealed no abnormality. When it was repeated at the age of thirty-five weeks, small calcified areas about one to two $\mathrm{mm}$. in diameter could be seen throughout the cortex, and a linear shadow in the region of the choroid plexuses (fig. 2). Air ventriculography showed a generalized dilatation of the ventricular system (fig. 3 ).

Serum of the mother and child was tested for toxoplasma antibody by Sabin in Cincinnati and was reported by him as unequivocally positive, the titre being $1: 1024$ in both sera, using the in vitro dye test (Sabin and Feldman, 1948). The father's serum gave a negative reaction. The cerebrospinal fluid of the child also contained the antibody in a titre of $1: 16$.

The maternal and child's blood Wassermann reactions were both negative. 


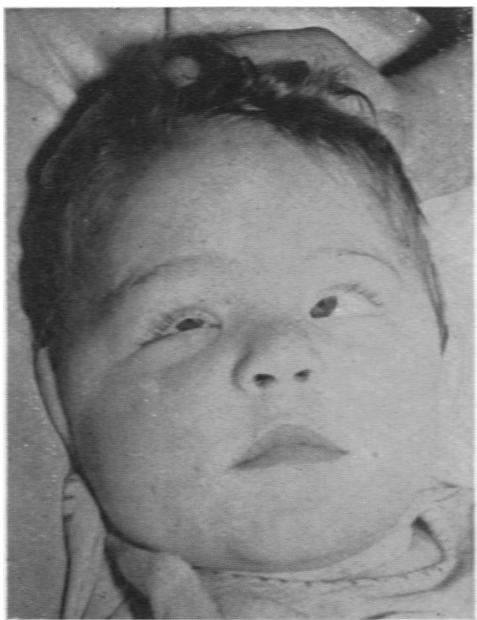

FIG. 1.-Case 1, showing facies and microphthalmos.

Fig. 2.-Case 1: calcified areas in cortex and linear shadow in region of choroid plexus.

Fig. 3.-Case 1: ventriculogram, showing generalized dilatation of ventricular system.

FIG. 1.

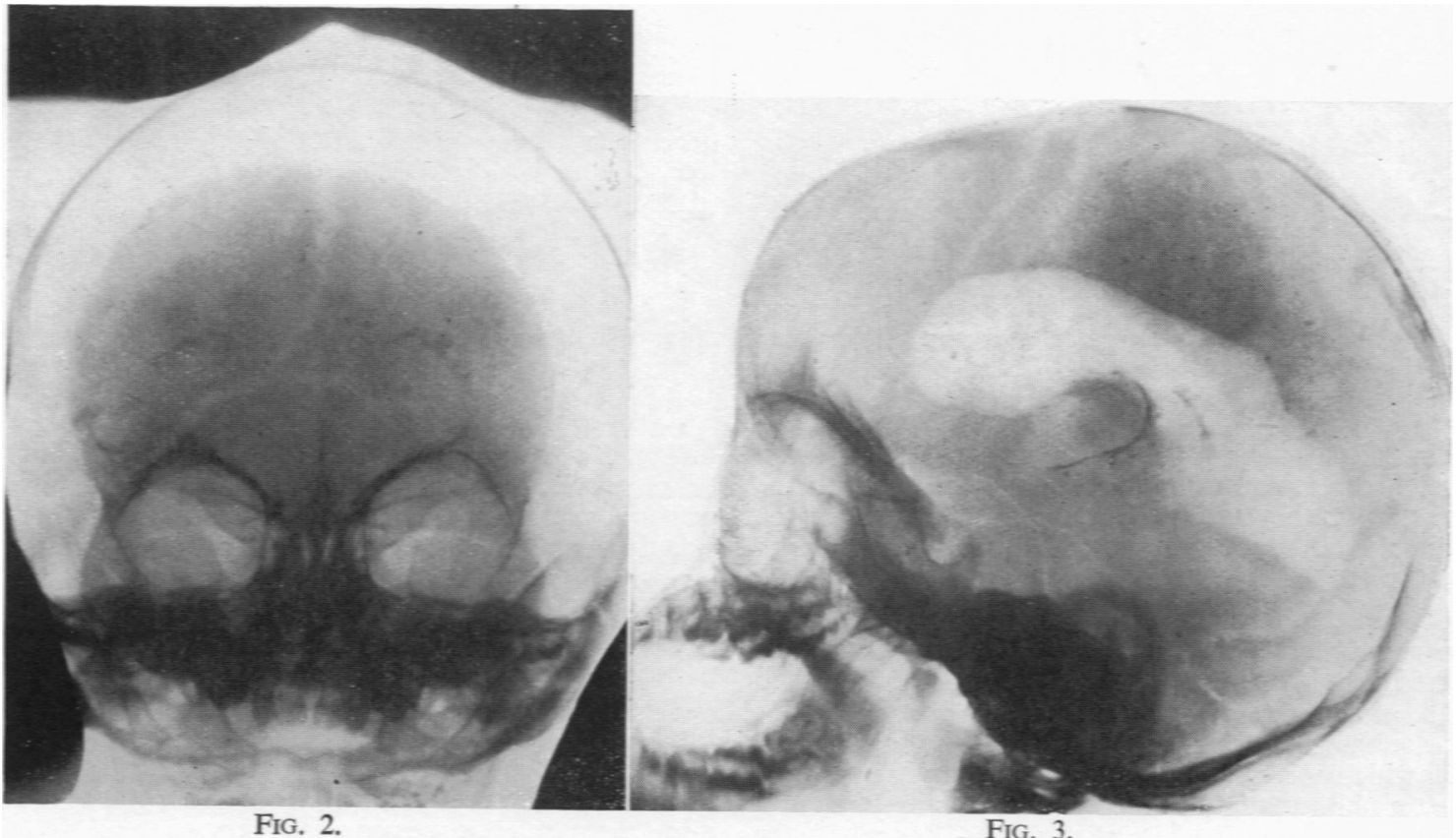

The child's blood showed moderately severe hypochromic anaemia, haemoglobin being 55 per cent. (alkaline haematin method 100 per cent. = 14.5 g. per cent.). Red blood cells numbered $4,800,000$ per c.mm. of blood. The white blood corpuscles showed no abnormality in number or relative proportions. The anaemia, resistant to iron therapy, responded to a transfusion of $180 \mathrm{ml}$. of blood, and the haemoglobin rose to 90 per cent. and remained at that figure.

The cerebrospinal fluid was clear and showed no xanthochromia (cells 3 per c.mm.; protein $10 \mathrm{mg}$. per $100 \mathrm{ml}$.; chlorides $740 \mathrm{mg}$.; sugar $54 \mathrm{mg}$.; no parasites were found in a centrifuged specimen).

Material from the needle used in performing the ventriculogram was examined microscopically but no protozoa were found. It is not at present possible to proceed further with these investigations owing to lack of available animals.

No abnormality was found in the urine or stools at any time.

Examination of the mother revealed no clinical abnormality, and a radiograph of her chest showed no lesions suggestive of toxoplasmosis. Twelve 

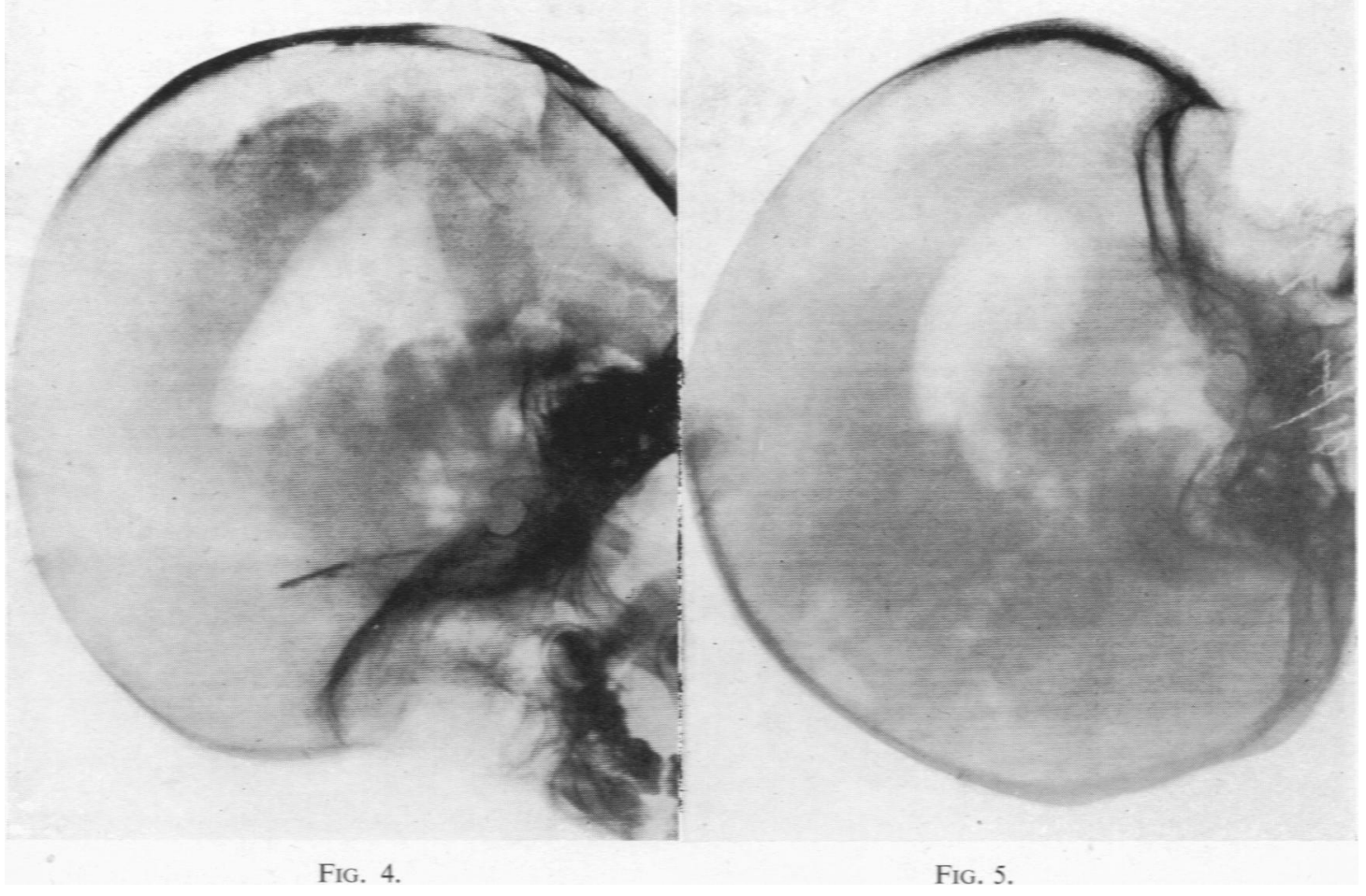

FIGs. 4 and 5.-Case 2: ventriculograms in prone position (fig. 4) and supine position (fig. 5), showing internal and external hydrocephalus.

days after having her blood taken for the estimation of toxoplasma antibody, and when five months pregnant, she had an abortion. Unfortunately we did not hear of this event until too late to obtain the specimen for examination.

Case 2. J.McC., a female infant, was born prematurely in the eighth month of pregnancy. At the twenty-sixth week of pregnancy the mother had an attack of what she called 'influenza.' This took the form of a pyrexial illness lasting a week in which the cervical lymph glands, and to a lesser extent those of the axillary and inguinal regions, became enlarged. Her doctor had described the illness as rubella without the rash. At the twentyeighth week, according to the mother, external version was performed for a breech presentation. Delivery was described as normal and the birth weight was $5 \mathrm{lb}$. At the age of three weeks the child had a temporary gastro-intestinal upset which lead to vomiting and diarrhoea lasting for four days and which recurred slightly in a week's time. This disorder coincided with the cessation of breast feeding and the giving of sweetened condensed milk and barley water to the child.

FAMILY HISTORY. The mother appeared to have been in good health all her life. She had, however, had a miscarriage when ten weeks pregnant four years previously, and had one daughter who was well and who had had no serious illness. The father was discharged from the R.A.F. following recurrent synovitis in his knee after the removal of a cartilage. He had been in West Africa during his service. There had been a dog in the house during the pregnancy, and there were said to be large numbers of cockroaches and mice.

The child first attended the out-patient department at the age of ten weeks for persistent vomiting of her feeds. The bowels had been normal since the alimentary upset at the age of three weeks.

Examination revealed a pale and hypotonic child weighing $6 \mathrm{lb}$. $14 \mathrm{oz}$. The only other abnormalities found at this time were a slight enlargement of the liver and vertical nystagmus of slight degree. A simple change in the feeding technique was sufficient to cure the condition, and the child returned in a week's time having gained weight satisfactorily.

She was next seen at the age of thirty-seven weeks, when the mother complained that she was not sitting up, was unable to grip anything held in front of her, and could not take solid foods.

Examination showed that the child weighed $16 \mathrm{lb} .14 \mathrm{oz}$. and was markedly backward mentally. 
Ophthalmic examination showed patches of choroidal degeneration in both eyes; in the right eye extending from the optic disc to the nasal side of the retina covering about one-sixth of the latter, and in the left eye extending on the temporal side of the disc over most of the retina, associated with much pigmentation and atrophy of the disc itself.

The child was admitted to hospital at the age of sixty-two weeks. The weight was now $18 \mathrm{lb}$., the incisor teeth had been cut, and the first molar teeth were just appearing. The mental retardation was still marked and according to the Gesell norms her developmental age was twenty-eight weeks. Sudden attacks of apparently causeless screaming occurred frequently but at no time did she show any convulsive tendency. The skull circumference was $15 \frac{1}{2}$ inches, and there was slight spasticity of all four limbs. The retinal lesions showed no change and no other abnormalities could be found in any system.

INVESTIGATIONS. A radiograph of the skull at the age of thirty-seven weeks had been reported as showing no calcification, but re-examination of this radiograph showed very slight and early changes of this kind. A repeat radiograph of the skull at the age of sixty-two weeks showed unmistakable calcification in the brain substance; there were multiple foci throughout the right parietal region of the brain, but these were too small $(1-2 \mathrm{~mm}$.) to reproduce in a photograph.

Air ventriculograms showed mild internal hydrocephalus but, as is best shown in the prone and supine films (figs. 4, 5), a marked external hydrocephalus was also present.

Serum reactions for toxoplasma antibody were investigated as before. The titre of the patient's serum was positive in a dilution of $1: 4096$, and that of both parents in $1: 1024$. The cerebrospinal fluid of the infant was positive in a dilution of only $1: 4$. The serum of the other child was unfortunately not reported upon.

The maternal and paternal blood Wassermann reactions were negative.

The child's blood showed mild hypochromic anaemia, the haemoglobin being 70 per cent. (alkaline haematin method 100 per cent. $=14.5 \mathrm{~g}$. per cent.), and the red cell count $4,400,00$ per c.mm. of blood. The white cell count on admission showed a neutrophil leucocytosis, the total white cells numbering 34,000 per c.mm.; the polymorphonuclear cells numbered 20,000, lymphocytes 13,000, and monocytes 680 . In two weeks' time the white cell count had become normal in all respects, and no cause for the previously high figure could be found. The haemoglobin remained at the same figure throughout.

The urine and stools were normal. The cerebrospinal fluid was clear, and contained 10 lymphocytes per c.mm., protein $20 \mathrm{mg}$. per $100 \mathrm{ml}$., chlorides $730 \mathrm{mg}$; ; the sugar was not estimated.
Biopsy material from the brain needles used in the performance of the ventriculograms was examined microscopically with negative results. Animal inoculation with this material was not carried out.

The mother and older child were both examined clinically and radiologically and no abnormalities were discovered. The father was not examined.

\section{Discuscion}

Though many of the criteria considered necessary for the diagnosis of congenital toxoplasmosis were present in the two cases which we have described, and the serum reactions were positive, yet it must be emphasized that up to the present time the parasite has not been isolated from these patients. It must be remembered, however, that isolation of the organism has proved to be difficult during the quiescent stage of the illness (Schwartzman et al., 1948); and as both our cases were probably quiescent at the time of testing, as shown by the extent of the calcification in the brain substance, the normal condition of the cerebrospinal fluid, and the inactivity of the ocular lesions, it is quite possible that even if we had been able to carry out animal inoculations our results might have been negative.

The significance of the serological tests for toxoplasmosis requires further consideration. The usual method, the neutralization test, demands a considerable amount of time, and, if large numbers are involved, a very great stock of animals. For this reason extensive studies do not appear to have been made. Callahan (1945) tested the sera of one hundred apparently normal people, seventy-seven of them being women between the ages of seventeen and twenty-four years, and twenty-three being men between the ages of twenty and twenty-eight years. He found the incidence of a positive neutralization test to be 2 per cent. in the whole group. Heidelman (1945), again using the neutralization test but with a selected group of patients, obtained the following results. Of twenty-seven patients with congenital toxoplasmosis, 63 per cent. were positive; of ninety-seven patients with anterior or posterior uveitis, 14 per cent. were positive; of nine patients with congenital chorioretinitis and other evidence of toxoplasmosis, 55 per cent. were positive; of seven mothers who had given birth to children with congenital chorioretinitis, six were positive. Of fifty-eight normal subjects, 10 per cent. had positive reactions. He conchudes that between 10 and 14 per cent. of subjects without any evidence of toxoplasmosis as at present understood are found to have antibodies against toxoplasma in their blood, and he suggests that in some at least the antibody may be non-specific. This figure of 10 per cent. for the general population corresponds closely to the conclusions of Sabin and Ruchman (1942). Johnson et al. (1946), testing a selected series of thirty-two patients all with a central type of chorioretinitis, found that 62 per cent. had neutralizing antibodies in their sera. 
From the above small number of cases it can be seen that a positive neutralization test does not necessarily imply that the patient is suffering from toxoplasmosis, nor, in our present state of knowledge, that he has ever had the infection. It is also clear from a study of the literature that the absence of a positive neutralization test does not exclude the diagnosis.

The serological tests in our two cases were performed by Dr. A. B. Sabin using a new technique that is to be published. We are not qualified to comment upon the details of this investigation, but Dr. Sabin's special experience of toxoplasmosis would seem to justify acceptance of his comment that the titres obtained were such as occurred only in proved recent cases of this infection.

\section{Conchusions}

It is probable that these two patients are suffering from congenital toxoplasmosis, and the finding of two such cases in one area within the period of six months raises the possibility that the condition may not be so rare as is at present believed. It would appear to us that the serological investigation of patients showing some or all of the manifestations of this disease, in particular mental retardation, microcephaly, and choroidoretinal degeneration in infancy, might well be extended in this country. An investigation of a cross-section of the population to determine the incidence of positive reactors and their further examination would be valuable.

\section{Summary}

Two cases showing the clinical manifestations of congenital toxoplasmosis have been described. Serum antibody reactions were positive, but the organism has not been isolated. It is suggested that the disease may be more frequent in this country than is at present believed, and that this possibility should be further investigated.

We wish to thank Prof. N. B. Capon for his valuable criticism and advice in the preparation of this paper; Dr. A. B. Sabin for his ready co-operation in the performance of the serological reactions; Drs. C. A. St. Hill, D. Mossman, and W. H. H. Andrews, for help in the pathological investigations; Mr. J. A. McCann for the ophthalmological reports; Mr. R. H. Hannah for the performance of the ventriculograms; and Dr. N. Walker for the radiological findings.

\section{REFERENCES}

Bamatter, F. (1946). Ann. paediatr., Basel, 19, 347.

Binkhorst, C. D. (1947). Maandschr. Kindergeneesk., $15,1$.

Boesen, I. (1948). Ugeskr. Laeg., 110, 226.

Callahan, W. P. (1945). Proc. Soc. exp. Biol., N.Y., $59,68$.

-, Russel, W. O., and Smith. M. G. (1946). Medicine, Baltimore, 25, 343.

Heidelman, J. M. (1945). Arch. Ophthal. Chicago, $34,28$.

Jacoby, N. M., and Sagorin, L. (1948). Lancet, 2, 926.

Janku, J. (1923). Časop. lék. česk., 62, 1021, 1054, 1081, 1111, 1138.

Johnson, L. V., Fried, N., Brundus, C. C., and Lamfrom, H. (1946). Arch. Ophthal. Chicago, 36, 677.

Magnusson, J. H. (1947). Svenska Läkart., 44/24, 1313.

Parsons, L. G. (1946). J. Obstet. Gynaec. Brit. Emp.,

Sabin, A. B. (1942). Advances in Paediatrics, 1, 1. New York.

—, and Ruchman, I. (1942). Proc. Soc. exp. Biol. N.Y., 51, 13.

- , and Feldman, H. A. (1948). Science. In the press.

Schwartzman, J., Maffia, A., Crusius, M. E., and Brunhoffer, A. (1948). 'J. Pediat., 33, 66.

Wolf, A., Cowen, D., and Paige, B. H. (1939a). Science, 89, 226.

(1939b). Amer. J. Path., 15, 657.

$\square, \square,-$ (1939b). Amer. J. Path., 15, 